\title{
The Environment Is a Key Factor in Determining the Anti-Amyloid Efficacy of EGCG
}

\author{
Tomas Sneideris ${ }^{1,+}+\mathbb{D}$, Andrius Sakalauskas ${ }^{1,+}+\mathbb{D}$, Rebecca Sternke-Hoffmann ${ }^{2,+}+\mathbb{C}$, \\ Alessia Peduzzo ${ }^{2}$ D, Mantas Ziaunys ${ }^{1}$ (D), Alexander K. Buell ${ }^{2,3} *$ (D) and Vytautas Smirnovas ${ }^{1, *(D)}$ \\ 1 Institute of Biothechnology, Life Sciences Center, Vilnius University, LT-10257 Vilnius, Lithuania; \\ sneideris.t@gmail.com (T.S.); sakalauskas.and@gmail.com (A.S.); mantas.ziaunys@gmail.com (M.Z.) \\ 2 Institute of Physical Biology, Heinrich-Heine-University, 40225 Düsseldorf, Germany; \\ Rebecca.Sternke-Hoffmann@uni-duesseldorf.de (R.S.-H.); alessia.peduzzo@uni-duesseldorf.de (A.P.) \\ 3 Department of Biotechnology and Biomedicine, Technical University of Denmark, \\ DK-2800 Kgs Lyngby, Denmark \\ * Correspondence: alebu@dtu.dk (A.K.B.); vytautas.smirnovas@bti.vu.lt (V.S.) \\ $\dagger$ These authors contributed equally to this work.
}

Received: 16 October 2019; Accepted: 6 December 2019; Published: 11 December 2019

\begin{abstract}
Millions of people around the world suffer from amyloid-related disorders, including Alzheimer's and Parkinson's diseases. Despite significant and sustained efforts, there are still no disease-modifying drugs available for the majority of amyloid-related disorders, and the overall failure rate in clinical trials is very high, even for compounds that show promising anti-amyloid activity in vitro. In this study, we demonstrate that even small changes in the chemical environment can strongly modulate the inhibitory effects of anti-amyloid compounds. Using one of the best-established amyloid inhibitory compounds, epigallocatechin-3-gallate (EGCG), as an example, and two amyloid-forming proteins, insulin and Parkinson's disease-related $\alpha$-synuclein, we shed light on the previously unexplored sensitivity to solution conditions of the action of this compound on amyloid fibril formation. In the case of insulin, we show that the classification of EGCG as an amyloid inhibitor depends on the experimental conditions select, on the method used for the evaluation of the efficacy, and on whether or not EGCG is allowed to oxidise before the experiment. For $\alpha$-synuclein, we show that a small change in $\mathrm{pH}$ value, from 7 to 6 , transforms EGCG from an efficient inhibitor to completely ineffective, and we were able to explain this behaviour by the increased stability of EGCG against oxidation at $\mathrm{pH} 6$.
\end{abstract}

Keywords: insulin; $\alpha$-synuclein; inhibition; EGCG; amyloid aggregation

\section{Introduction}

The onset and progression of more than 50 human disorders, including the neurodegenerative Alzheimer's and Parkinson's diseases (AD and PD), is associated with the failure of peptides and proteins to adopt or remain in their native functional and soluble states, and their subsequent conversion into amyloid fibrils [1,2]. Millions of people around the world suffer from these disorders; $\mathrm{AD}$ alone affects 40 million patients worldwide and is projected to rise steadily to afflict 135 million people by 2050 [3,4]. Distinct peptides and proteins are associated with these particular human disorders; however, the formation and accumulation of insoluble fibrillar aggregates are common among these diseases [1,2]. Whether extracted from patients or generated in vitro, amyloid fibrils formed from different proteins seem to be remarkably similar in overall morphology. Mature amyloid fibrils tend to appear as unbranched, thread-like, elongated structures, several nanometres in diameter and with lengths of the order of micrometres [1,2]. In addition, the corresponding fibrils all contain a $\beta$-sheet-rich structure, termed "cross- $\beta$," according to the pattern in X-ray fibre diffraction studies [5]. 
Several therapeutic approaches, such as a reduction in the production of amyloidogenic peptides, the increase of the native state stability of amyloidogenic proteins, an enhancement in the clearance rates of misfolded proteins, and a direct inhibition of the self-assembly process, have been suggested for treatment of amyloid-related disorders [6-12]. Numerous small molecular weight compounds, short peptides, and antibodies have been suggested as potential modulators and inhibitors of toxic oligomeric and fibrillar species' assemblies [6,8,9,12-15]. Despite significant and persistent efforts, there are still no effective disease-modifying drugs or treatment modalities available for the majority of amyloid-related disorders (overall success rate of clinical trials is $<0.5 \%$ ) [16-21].

The formation of amyloid fibrils is a complex process, which involves several microscopic steps (e.g., nucleation, growth, fragmentation, and secondary nucleation) [1,2]. Alterations in environmental conditions can modulate these microscopic steps, resulting in different pathways and leading to the formation of structurally distinct amyloid aggregates [1,22-25]. Such conformational variability, also known as polymorphism, is thought to be a generic property of amyloid proteins, and has been proposed to be able to cause distinct disease phenotypes $[1,26,27]$. Moreover, the effects of potential therapeutic agents can vary depending on the conditions in which they are assayed (i.e., $\mathrm{pH}$, temperature, buffer, interfaces, agitation, and others) [12], possibly due to chemical modifications of potential therapeutic molecules [28-30]. Since the environmental conditions under which aggregation of amyloid proteins is performed can vary between distinct studies, the search and assessment of potential inhibitors becomes extremely challenging, as the results may lead to diverse conclusions.

An ideal amyloid assembly inhibitor should act as broadly as possible and be capable of interacting with different species along the pathway of aggregation. The desired outcome of such an interaction is to block the formation of toxic oligomeric species and to possibly dissociate preformed fibrillar aggregates into non-toxic species [31]. Epigallocatechin-3-gallate (EGCG), the main polyphenol found in green tea, has been reported to effectively inhibit the aggregation of a number of amyloidogenic peptides and proteins, including amyloid- $\beta$ (related to AD) [32,33], $\alpha$-synuclein (related to PD) [33-36], islet amyloid polypeptide (related to type-II diabetes) [37,38], huntingtin exon 1 (related to Huntington's disease) [39], tau (related to AD and tauopathies) [40], superoxide dismutase (related to amyotrophic lateral sclerosis) [41], prion proteins (related to prion diseases) [42], and others. In addition, it has been shown that EGCG can induce remodeling and/or dissociation of pre-existing aggregate species $[33,34,36,43,44]$. Taken together, EGCG appears to be a "universal" inhibitor of amyloid fibril formation, suggesting that this molecule could be used as a therapeutic agent for the prevention and treatment of amyloid-related disorders. However, EGCG is not stable at neutral or alkaline pH [45-48], where it is susceptible to auto-oxidation, resulting in the formation of numerous products [28] which may differently affect amyloid aggregation $[29,30,49]$.

In this study, we set out to explore whether or not the universal nature of EGCG as an inhibitor is robust against variation in solution conditions. We chose two amyloid forming protein systems, a model system (insulin) and a disease-related protein ( $\alpha$-synuclein), which form amyloid fibrils under very different solution conditions. This choice allowed us to separately probe the influence of EGCG oxidation and the interplay between the solution conditions and the action of EGCG.

The formation of insulin amyloid fibrils in vivo is associated with the clinical syndrome injection-localised amyloidosis, which was observed in diabetes patients after continuous subcutaneous injections of insulin [50,51]. Despite its main application in medicine, recombinant human insulin is also extensively used as a model protein to study pathways and mechanisms of amyloid fibril formation in vitro. It has been demonstrated that several sets of conditions, including the presence of ethanol [52-54]; different pHs [22,55] or salt concentrations [23,55]; and agitation [55,56], can alter insulin aggregation pathways and even lead to the formation of structurally different amyloid fibrils. The majority of insulin aggregation studies were performed at low $\mathrm{pHs}$, which do not reflect the physiological environment, but serve to significantly accelerate amyloid fibril formation through a destabilisation of the native state. At the same time, acidic conditions are known to lead to higher EGCG stability against oxidation. We demonstrate the different effects of EGCG and its auto-oxidation 
products $\left(\mathrm{EGCG}_{o x}\right)$ on insulin aggregation. Furthermore, we show that even under the acidic reaction conditions where EGCG is stable, the exact solvent conditions determine whether or not EGCG is able to modulate the kinetics of insulin amyloid fibril formation.

The strong $\mathrm{pH}$-dependence of EGCG's stability against oxidation in the proximity of neutral $\mathrm{pH}$ enabled us to probe the interplay of protein aggregation and EGCG oxidation, using the protein $\alpha$-synuclein, associated with Parkinson's disease [57]. By comparing $\alpha$-synuclein amyloid fibril formation at $\mathrm{pH}$ 7, where EGCG rapidly oxidises, and $\mathrm{pH}$ 6, where it is much more stable, we found that EGCG converts from an efficient inhibitor at $\mathrm{pH} 7$ to being completely ineffective at $\mathrm{pH} 6$. On the other hand, pre-oxidised EGCG is a very powerful inhibitor at pH 6 as well. Taken together, in this study we demonstrate that even an inhibitor candidate as well-characterised as EGCG can display a dramatically different inhibitory efficiency depending on the solution conditions, and hence a systematic exploration of the interplay of solution conditions and compound stability and efficacy is crucial.

\section{Results}

We first performed insulin amyloid fibril formation experiments under different acidic solution conditions. When the insulin aggregation reaction was performed in $100 \mathrm{mM}$ phosphate buffer, $\mathrm{pH}$ 2.4 (PB), under quiescent conditions, the presence of EGCG increased the half-time $\left(t_{50}\right)$, i.e., the time to reach half the maximal Thioflavin-T (ThT) fluorescence intensity, by almost two-fold, while at the same time decreasing the maximum fluorescence intensity $\left(I_{\max }\right)$ nearly two-fold, when compared to the control (Figures 1 and S1). The effect of $\mathrm{EGCG}_{0 x}$ (see Methods section for experimental protocol to generate oxidised EGCG) is stronger, and leads to an almost four times longer $t_{50}$ and almost four times lower $I_{\max }$. In the Supplementary Material, we show time-resolved UV-Vis data of EGCG that demonstrates the lack of oxidation under the conditions of these kinetic experiments (Figure S2). Under agitated conditions in PB, EGCG has no inhibitory effect, while EGCG Ex $_{0 x}$ has a minor effect on the insulin aggregation process (Figures 1 and S1).
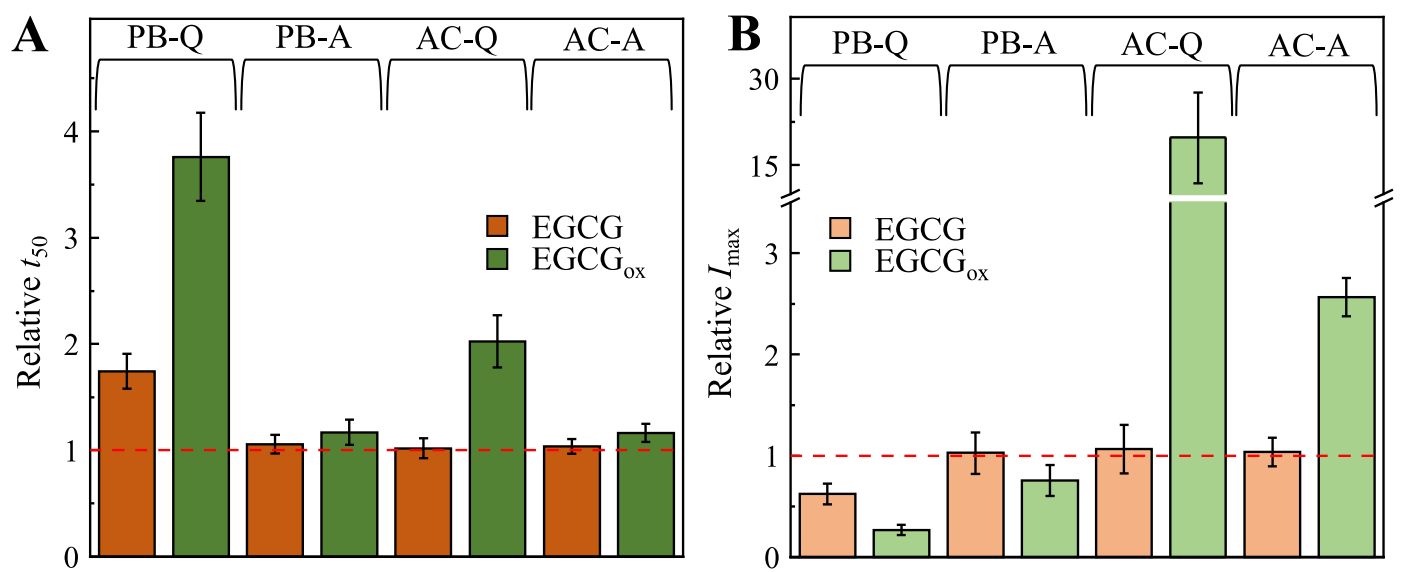

Figure 1. Effects of EGCG and EGCG $0 x$ on insulin aggregation kinetics (A) and maximum ThT fluorescence intensity (B). Abbreviations PB and AC represent environmental conditions (100 mM phosphate buffer and 20\% acetic acid, respectively), while $Q$ and A denote the agitation conditions (quiescent and agitated, respectively), under which the insulin aggregation reactions were performed. Error bars represent standard deviations.

The presence of EGCG ${ }_{0 x}$ results in a two times longer $t_{50}$ and 20 times higher $I_{\max }$ effect, when the aggregation reaction is performed in $20 \%$ acetic acid (AC), under quiescent conditions (Figure 1 ). When agitation is applied, the presence of EGCG ${ }_{0 x}$ results in a three times higher $I_{\max }$ and has a minor effect on $t_{50}$ (Figures 1 and S1). The presence of non-oxidised EGCG has no effect on $t_{50}$ or $I_{\max }$, when the aggregation reaction is performed under either quiescent or agitated conditions (Figures 1 and S1) in AC. Taken together, these results suggest that under these sets of solution conditions, EGCG has only a weak effect on insulin amyloid fibril formation, which is reinforced by oxidation of EGCG. 
Furthermore, the results also suggest that the absolute fluorescence intensity of ThT bound to insulin amyloid fibrils is strongly influenced by the presence of $\mathrm{EGCG}_{0 x}$.

Sample analysis using atomic force microscopy (AFM) confirmed the formation of insulin amyloid fibrils within $15 \mathrm{~h}$ under all test conditions (Figure 2, Figures S3-S6). Typically, individual fibrils are $3-10 \mathrm{~nm}$ in height and their lengths range from several hundred $\mathrm{nm}$ to several $\mu \mathrm{m}$. In PB, insulin amyloid fibrils tend to cluster, and larger bundles were apparent when the reaction was performed under agitated conditions. In the presence of $\mathrm{EGCG}_{o x}$, the fibrils seem to be more dispersed (Figure 2, Figures S3 and S4). In AC more fibrils can be seen in the presence of EGCG when compared to the control sample (Figure 2, Figures S5 and S6), even though care must be taken when quantitatively comparing AFM images and correlating these results with the composition of the solution. Fibrils formed in the presence of EGCG under all environmental conditions are similar in morphology to their respective control samples; i.e., the absence of EGCG or EGCG $\mathrm{E}_{0 x}$.
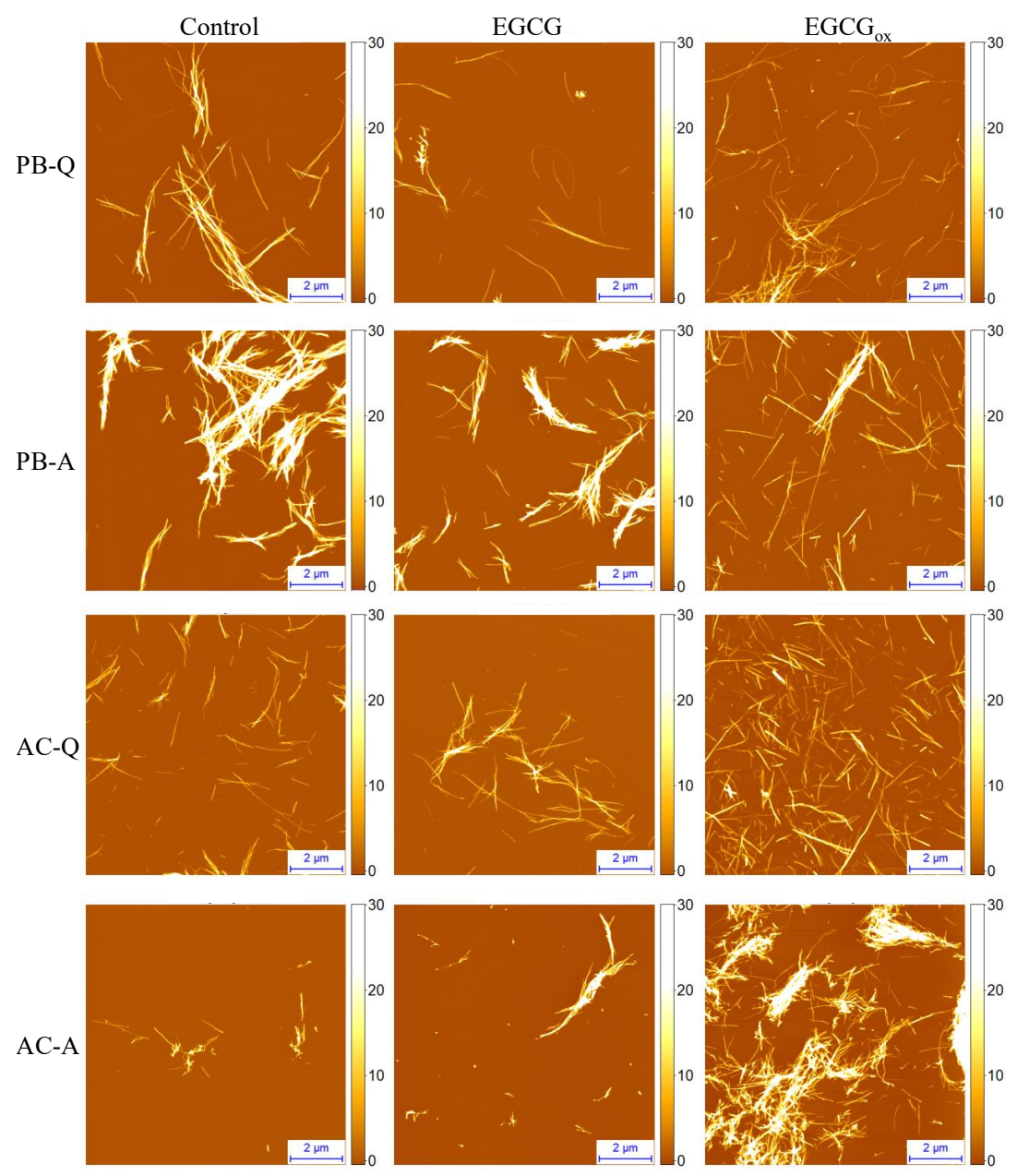

Figure 2. AFM images of insulin amyloid fibrils formed in PB or AC in the absence and presence of EGCG or $\mathrm{EGCG}_{0 x}$. Abbreviations Q and A denote agitation conditions (quiescent and agitated, respectively), under which the insulin aggregation reactions were performed. The height scale $(z)$ is in $\mathrm{nm}$.

The secondary structure of insulin amyloid fibrils was assessed using Fourier-transform infrared (FTIR) spectroscopy (Figure 3). Second derivative FTIR spectra of fibrils formed in AC under quiescent and agitated conditions are almost identical, both showing a major minimum at $1627 \mathrm{~cm}^{-1}$ and a minor one at $1641 \mathrm{~cm}^{-1}$ in the amide I/I' region, attributed to $\beta$-sheet structure and an additional band at $1729 \mathrm{~cm}^{-1}$ (Figure 3), which was assigned to the stretching vibrations of a deuterated carboxyl group (-COOD) [58]. Similarly, a major minimum at $1627 \mathrm{~cm}^{-1}$ in the amide I/I' region, is present in case of $\mathrm{PB}$ under agitated conditions; however, the other two minima observed in AC are missing. The second 
derivative FTIR spectrum of insulin amyloid fibrils formed in PB under quiescent conditions has two minima at $1625 \mathrm{~cm}^{-1}$ and $1637 \mathrm{~cm}^{-1}$ in the Amide I/I' region. It confirms that fibrils formed without agitation in PB are structurally different from fibrils formed in AC, while the fibrils formed in PB with agitation seem to have a secondary structure profile, which looks like an intermediate between $\mathrm{PB}$ and AC. These results suggest that despite the very similar morphology, as judged from AFM images, the insulin amyloid fibrils formed under different solvent conditions have some structural differences.

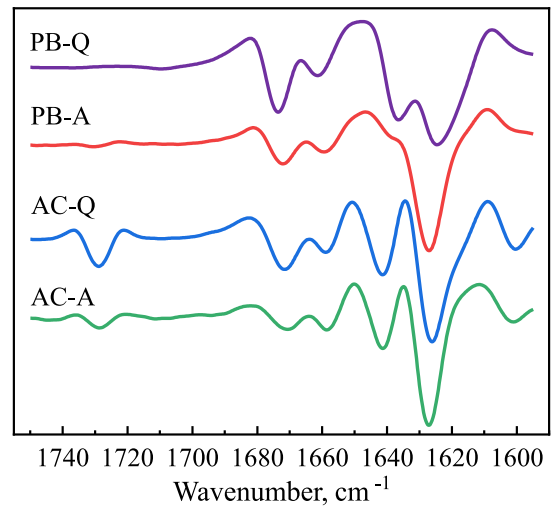

Figure 3. Second derivative FTIR spectra of insulin amyloid-like aggregates formed in PB and AC under quiescent and agitated conditions. Abbreviations $\mathrm{PB}$ and $\mathrm{AC}$ represent environmental conditions (100 mM phosphate buffer and 20\% acetic acid, respectively), while $Q$ and A denote agitation conditions (quiescent and agitated, respectively), under which the insulin aggregation reaction was performed.

The insulin aggregation experiments under acidic conditions described above allow one to isolate the oxidation of EGCG from the protein aggregation. However, in many cases, amyloid fibril formation is studied under conditions under which EGCG is highly unstable. We therefore performed additional amyloid fibril formation experiments with $\alpha$-synuclein, the aggregation of which is associated with Parkinson's disease [57]. $\alpha$-synuclein forms amyloid fibrils at both neutral and mildly acidic $\mathrm{pH}$ [25], which provides an ideal paradigm to study the inhibition by EGCG, because the latter compound displays a dramatic change in stability between neutral and slightly acidic $\mathrm{pH}$ (Figure S2). We incubated monomeric $\alpha$-synuclein in polystyrene plates under shaking, and in the presence of glass beads. Under these conditions, the surface-catalysed nucleation [59] and subsequent amplification through fragmentation [25] of $\alpha$-synuclein amyloid fibrils is very efficient. We compared the time course of ThT fluorescence at $\mathrm{pH} 7$, where it has been shown that EGCG is an efficient inhibitor of $\alpha$-synuclein amyloid fibril formation [33], and at the slightly more acidic pH of 6 (Figure 4A,B). We found that, based on ThT intensity alone, at pH 7, EGCG completely inhibits the formation of $\alpha$-synuclein amyloid fibrils at a stoichiometric ratio of 1:1, whereas at $\mathrm{pH} 6$, the maximal ThT intensity is merely reduced by a factor of two, while the half time is very similar compared to the absence of EGCG.

AFM images (Figure 5) show amyloid fibrils at pH 7 without EGCG and at pH 6 both in the presence and absence of EGCG. At pH 7 in the presence of EGCG, AFM imaging reveals some amorphous aggregates together with very short fibrillar structures, and in the presence of $\mathrm{EGCG}_{0 x}$, almost no fibrils are found. The situation is dramatically different at $\mathrm{pH} 6$, where fibrils can clearly be seen under all conditions, albeit very few in the presence of EGCG $0 x$, where ThT fluorescence is completely suppressed. In order to obtain an independent measure for the degree of inhibition of aggregation by EGCG and EGCG Ex $_{0}$, we centrifuged the samples after the aggregation experiment and quantified the average size and concentration (Figure $4 \mathrm{C}$ ) of the soluble protein by microfluidic diffusional sizing (MDS) $[60,61]$ (see Methods section for details). We found that in the absence of EGCG, both at $\mathrm{pH} 7$ and $\mathrm{pH}$ 6, the protein converts near-quantitatively into aggregates, whereas in the presence of EGCG and EGCG Ex $_{0}$, nearly all of the protein remains soluble, and display average hydrodynamic radii of $\sim 2.3 \mathrm{~nm}$ at $\mathrm{pH} 6$ and $\sim 2.7 \mathrm{~nm}$ at $\mathrm{pH} 7$, indistinguishable from measurements of 
pure monomeric protein and in close agreement with previous measurements under similar solution conditions [62]. Interestingly, at pH 6, MDS reveals that EGCG has no effect on the conversion efficiency into aggregates, and even in the presence of $\mathrm{EGCG}_{o x}$, inhibition is only partial, despite the fact that ThT fluorescence is completely quenched. We also accompanied these experiments by UV-Vis spectroscopic stability studies of EGCG under the same solution conditions, and we found that while the EGCG absorption spectrum undergoes substantial changes at $\mathrm{pH} 7$ already after $1 \mathrm{~h}$, almost no change is observed at $\mathrm{pH} 6$ after almost 1 day of incubation (Figure S2).
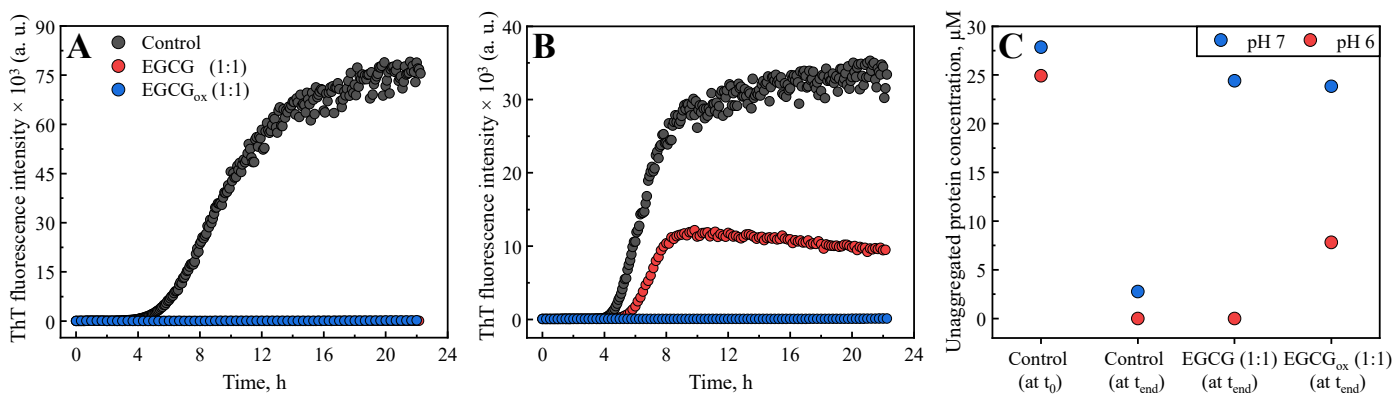

Figure 4. The effects of EGCG and EGCG $0 x$ on the aggregation kinetics of $\alpha$-synuclein monitored at $\mathrm{pH}$ 7 (A) and pH 6 (B). (C) $\alpha$-synuclein concentration measured in the supernatant after centrifuging the end product of the aggregation reactions at $\mathrm{pH} 7$ and $\mathrm{pH} 6$, respectively.
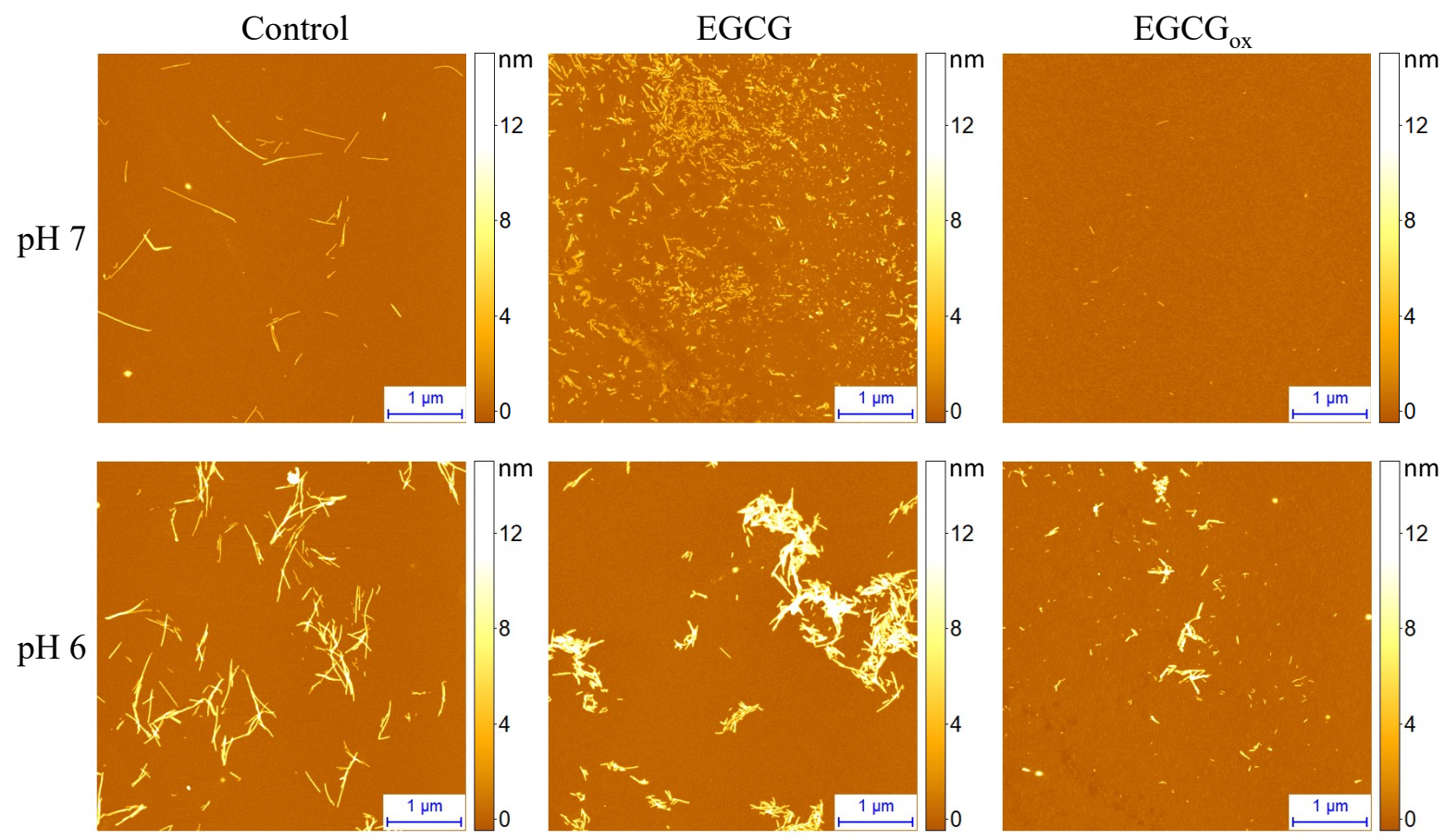

Figure 5. AFM images of $\alpha$-synuclein aggregates formed at $\mathrm{pH} 7$ or $\mathrm{pH} 6$ in the absence and presence of EGCG or $\mathrm{EGCG}_{0 x}$.

\section{Discussion and Conclusions}

The effects of potential inhibitor compounds on the process of amyloid fibril formation are often determined by analysing the kinetics of aggregation $[15,29,30,32,33,63-68]$ and/or the maximum ThT intensity $[29,30,32,33,65,67-71]$ in the absence and presence of the compound. The effects of EGCG and EGCG $0 x$ on the process of amyloid fibril formation by both insulin and $\alpha$-synuclein performed under distinct environmental conditions were assessed using both aforementioned approaches (Figures 1 and S7), and the conclusions are presented in (Table 1). In the case of insulin, if $t_{50}$ and/or $I_{\max }$ were used as the main criteria, EGCG could be defined as an inhibitor of amyloid formation 
only if the screening was performed in PB under quiescent conditions. In case of $\mathrm{EGCG}_{0 x}$ the picture is more complex. In PB, EGCG $E_{0 x}$ was found to be an inhibitor independently of the assessment criteria, whereas in $\mathrm{AC}, t_{50}$ points towards an inhibitory effect, while $I_{\text {max }}$ suggests an enhancement of aggregation. In the case of $\alpha$-synuclein amyloid fibril formation, on the other hand, both criteria suggest EGCG to be a strong inhibitor at $\mathrm{pH} 7$, whereas only $I_{\text {max }}$ indicates inhibition at $\mathrm{pH}$. In the latter case, only the inclusion of the soluble protein at the end of the reaction as an additional measured parameter allows to correctly evaluate the inhibitory effect. These results suggest that depending on aggregation conditions and the screening criteria, the same compound could be defined as a hit or a failure. This raises the question as to the origin of such variable results.

Table 1. Evaluation of EGCG and EGCG ox $^{\prime}$ s effects on the insulin aggregation process.

\begin{tabular}{cccc}
\hline \multicolumn{4}{c}{ Assessed by Change in $t_{50}$} \\
\hline Protein & Conditions & EGCG & EGCG $_{\text {ox }}$ \\
\hline \multirow{4}{*}{ Insulin } & PB-Q & Inhibitory & Inhibitory \\
& PB-A & No Effect & Inhibitory \\
& AC-Q & No Effect & Inhibitory \\
& AC-A & No Effect & Inhibitory \\
\hline \multirow{2}{*}{$\alpha$-synuclein } & pH 7 & Inhibitory & Inhibitory \\
& pH 6 & No Effect & Inhibitory \\
\hline \multirow{4}{*}{ Protein } & Assessed by Change in I $_{\text {max }}$ & \\
\hline \multirow{4}{*}{ Insulin } & Conditions & EGCG & EGCG \\
& PB-Q & Inhibitory & Inhibitory \\
& PB-A & No Effect & Inhibitory \\
& AC-Q & No Effect & Enhancing \\
& AC-A & No Effect & Enhancing \\
\hline \multirow{2}{*}{$\alpha$-synuclein } & pH 7 & Inhibitory & Inhibitory \\
& pH 6 & Inhibitory & Inhibitory \\
\hline
\end{tabular}

${ }^{1}$ Established by comparing experimental values of $t_{50}$ or $I_{\max }$ of control samples with the ones determined in the presence of EGCG or EGCG $0 x$ using one-way ANOVA (See Figure S7). $p<0.01$ was accepted as statistically significant.

First, alterations in environmental conditions can modulate protein aggregation pathways and result in the formation of structurally distinct amyloid aggregates (Figure 6A) [22-24,26,27]. Thus, it is plausible that species targeted by the compound might exist only under certain environmental conditions. Indeed, EGCG inhibits the insulin aggregation reaction only when the latter is performed in PB under quiescent conditions. AFM analysis did not reveal any major differences between fibrils formed in the absence or presence of EGCG (Figure 2). However, differences in the secondary structure of fibrils, determined using FTIR (Figure 3), suggest the possibility of distinct pathways and intermediates involved in the process of insulin fibril formation in PB under quiescent or agitated conditions or in AC under both the presence and absence of agitation. It is possible that the molecular species targeted by EGCG or its oxidation products are only present under certain environmental conditions. A similar explanation can be valid for the different relative $t_{50}$ values in $\mathrm{PB}$ and $\mathrm{AC}$ in the presence of $\mathrm{EGCG}_{0 x}$. The strong increase in ThT fluorescence intensity in the presence of $\mathrm{EGCG}_{0 x}$ in $\mathrm{AC}$, on the other hand, requires an alternative explanation. A simple increase in the quantity of fibrils formed is not sufficient to explain the observed several-fold increase in $I_{\text {max }}$. It has been demonstrated before that amyloid fibrils formed under distinct environmental conditions may possess different ThT binding sites, affinities for ThT, and ThT quantum yields [72-74]. Thus, since the secondary structure of insulin amyloid fibrils formed in $\mathrm{PB}$ and $\mathrm{AC}$ was found to be different (Figure 3), it is possible that EGCG $_{o x}$ induces slight conformational changes in the amyloid fibrils formed in AC, which results in an increase in quantum yield in the bound ThT, and therefore, in increased ThT fluorescence intensity. However, no obvious differences in morphology or secondary structure (Figures S5, S6 and S8), of 
insulin fibrils formed in AC in the absence or presence of $\mathrm{EGCG}_{0 x}$ were observed. Therefore, it is also possible that the change in ThT intensity stems from a direct interaction between bound ThT and $\mathrm{EGCG}_{o x}$. The fact that extrinsic compounds can dramatically change the ThT fluorescence quantum yield has sometimes led to false interpretation of a given compound as an inhibitor (Figure 6B). It has, for example, been shown that the two amyloid dyes, Congo red (CR) and ThT, have an affinity for each other and that CR strongly quenches ThT fluorescence, rather than inhibiting amyloid fibril growth [75]. Therefore, absolute fluorescence intensity is often not a reliable readout for the extent of inhibition by any given compound. This conclusion is further supported by the results obtained for $\alpha$-synuclein at $\mathrm{pH}$, where the final ThT intensity in the presence of EGCG suggests a significant inhibition, but measurement of soluble protein and AFM show that the sample has quantitatively been converted into fibrils. The nature of the surfaces involved (cuvette, plate surface, stir bar, and air-water-interface), in combination with the physico-chemical properties of the protein can also have a large impact on the protein aggregation process [59,76-79]. Indeed, additional experiments showed that the strong increase in $I_{\max }$ observed in the presence of $\mathrm{EGCG}_{0 x}$ depends on the type of surface of the microplate used (Figure S9). Under agitated conditions the effect of EGCG Ex $_{0}$ on insulin aggregation was found to be weaker when compared to the one under quiescent conditions. Agitation in general speeds up amyloid fibril formation, mostly because of its effect on fibril fragmentation, and the detachment of species from the air-water or solid-water interface, where proteins have a strong tendency to accumulate and where in many cases the nucleation step of amyloid fibril formation is likely to occur. By selectively enhancing individual steps, such as fragmentation or nucleation, the concentrations of species that can be targeted by EGCG may be decreased, and hence, its inhibitory effect diminished.

Second, specific environmental conditions may induce modifications of compounds (Figure 6C) [28-30,80]. For example, EGCG is not stable at neutral pH and oxidises within several hours. In general, the effect of $\mathrm{EGCG}_{0 x}$ on insulin aggregation, is stronger when compared to its non-oxidised form. A further striking example of the effect of the solution conditions on the inhibitory effects of EGCG is given by our findings that a change in $\mathrm{pH}$ by only one unit dramatically changes the inhibition of $\alpha$-synuclein amyloid fibril formation. At the most often employed neutral $\mathrm{pH}$ of 7 , where EGCG is highly unstable, almost complete inhibition is observed by stoichiometric amounts of EGCG, as evaluated by ThT fluorescence and microfluidic diffusional sizing (MDS). At the same time, UV-Vis experiments with EGCG under equivalent conditions show that EGCG undergoes rapid and quantitative oxidation within a similar time scale as the aggregation process itself (Figures S2 and 6C). This leads to the fact that mostly oxidised EGCG is available to inhibition. The effect of EGCG and $\mathrm{EGCG}_{0 x}$ at $\mathrm{pH} 7$ is to keep the protein in its monomeric form, as has recently also been reported [81]. The amorphous aggregates that have been observed to be formed by $\alpha$-synuclein in the presence of EGCG at neutral $\mathrm{pH}$ could stem in part from monomeric protein that clusters into amorphous structures during sample preparation for AFM or electron microscopy. We note that even under these conditions of near complete inhibition, as evaluated by ThT fluorescence and MDS, some short fibrils can be seen in AFM images, stressing the importance of the use of multiple experimental methods in order to obtain a complete picture of the inhibitory action. A change to $\mathrm{pH}$, however, leads to an increased stability of EGCG (as confirmed by UV-Vis spectroscopy, Figure S2), which is paralleled by a strongly decreased inhibitory effect on $\alpha$-synuclein aggregation. Indeed, despite the fact that ThT fluorescence intensity is decreased by approximately 50\% in the presence of stoichiometric amounts of EGCG and quantitatively suppressed in the presence of stoichiometric amounts of EGCG ox, $\mathrm{MDS}$ and AFM suggest no inhibition by EGCG and only partial inhibition by EGCG Ex . These results not only suggest an influence of EGCG and $\mathrm{EGCG}_{0 x}$ on ThT fluorescence intensity (Figure 6B), but most notably a dramatic pH dependence of the inhibitory effect of EGCG, most likely related to EGCG stability, as discussed above. This finding is highly relevant and interesting, as $\alpha$-synuclein experiences environments with reduced $\mathrm{pH}$ during its life cycle, such as endosomes and lysosomes [82,83]. Furthermore, it has been shown that the aggregation of $\alpha$-synuclein is strongly enhanced at mildly acidic $\mathrm{pH}$ values [25], as found in such microenvironments, whereas at the same time EGCG appears to lose its inhibitory effect. In conclusion, 
we demonstrate here that the environmental conditions and the methods used for assessments of the effects of inhibitory compounds play an important role in the reliable identification of anti-amyloid compounds. Under certain circumstances the study design may define whether a given compound is found to be a hit or a failure. Therefore, assessing the effects and the intrinsic stability of compounds under a range of environmental conditions in vitro is essential for the further development of the lead compounds resulting in increased success rates for in vivo studies and clinical trials.

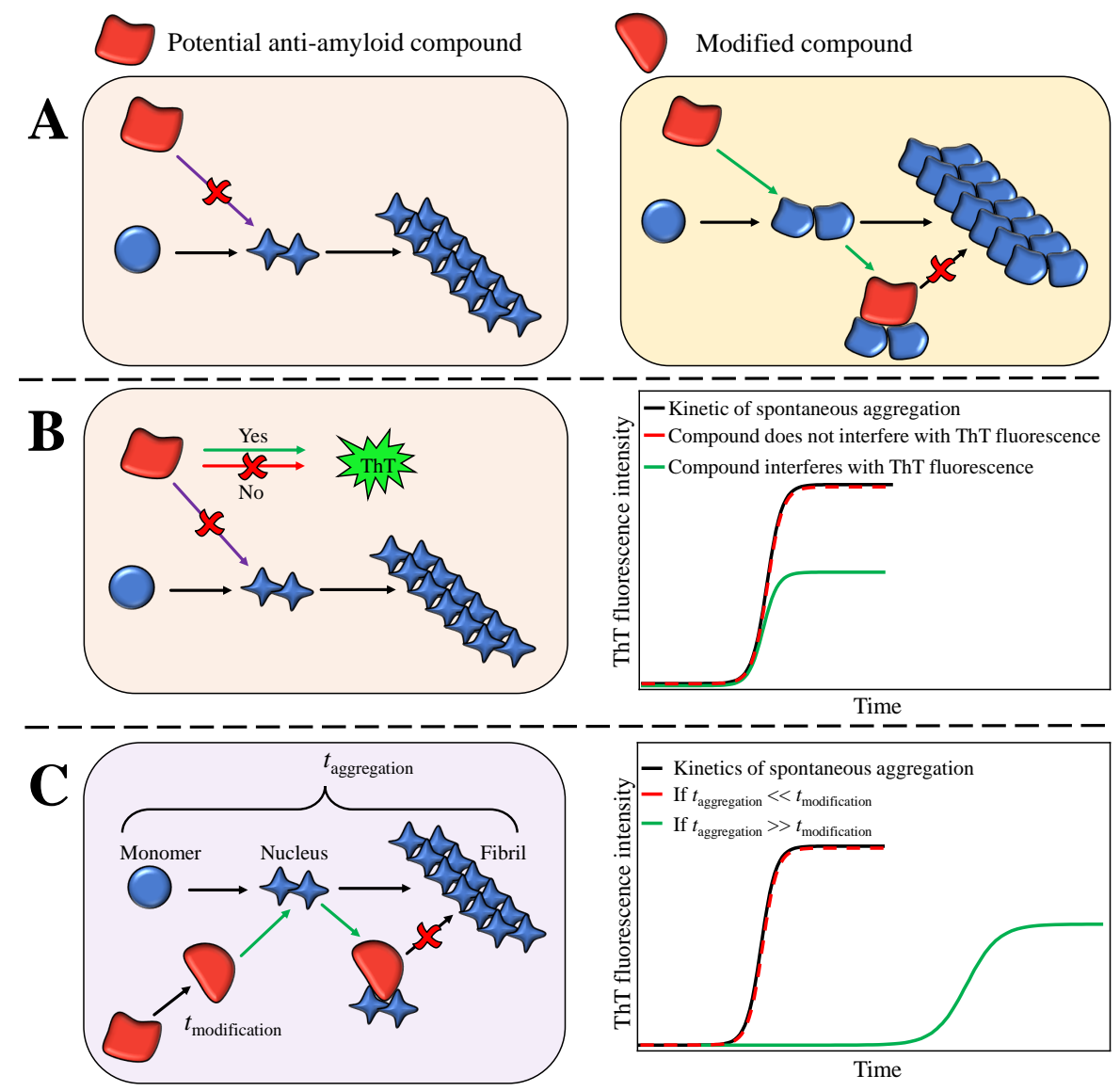

Figure 6. Schematic depiction of possible effects of potential anti-amyloid compounds on the amyloid aggregation reaction performed under distinct environmental conditions. Different environmental conditions can lead to the formation of distinct aggregate species of which only some are targeted by the compound (A), as in case of insulin aggregation in PB-Q and AC-Q. Certain compounds can also interfere with ThT's fluorescence intensity (B), suggesting inhibition, which was not confirmed by other experiments, such as the quantification of soluble protein at the final plateau of ThT intensity. An example is EGCG and $\alpha$-synuclein at pH 6. Moreover, specific environmental conditions can induce modifications of the compound, which results in the generation of products that target aggregation prone species (C), as in the case of $\alpha$-synuclein aggregation at neutral $\mathrm{pH}$. The compound modification can only manifest itself if it occurs with kinetics comparable to, or faster than the kinetics of aggregation. Distinct background colours represent different environmental conditions. Different shapes of aggregates represent distinct pathways reflecting the observed polymorphism of amyloid fibrils.

\section{Materials and Methods}

\subsection{Materials and Solutions}

Initial solutions of insulin (Sigma Aldrich, St. Louis, MO, USA, number 91077C) were prepared by dissolving $2 \mathrm{mg}$ of dry insulin powder in $0.5 \mathrm{~mL}$ of $100 \mathrm{mM}$ sodium phosphate buffer, $\mathrm{pH} 2.4$, supplemented with $100 \mathrm{mM} \mathrm{NaCl}(\mathrm{PB})$ or $20 \%$ acetic acid, supplemented with $100 \mathrm{mM} \mathrm{NaCl}(\mathrm{AC})$. 
Concentration of insulin (M.W.- $5808 \mathrm{Da}, \varepsilon_{280}-6335 \mathrm{M}^{-1} \mathrm{~cm}^{-1}$ ) was determined by measuring UV-absorption at $280 \mathrm{~nm}$ using NanoDrop 2000 (Thermo Fisher Scientific, Wolsom, MA, USA). Subsequently, insulin solutions were diluted to a final concentration of $2 \mathrm{mg} / \mathrm{mL}(344 \mu \mathrm{M})$ using PB or AC and supplemented with $200 \mu \mathrm{M}$ of Thioflavin-T (ThT; Sigma Aldrich, number T3516) from a $10 \mathrm{mM}$ ThT stock solution (in MilliQ water). For the insulin inhibition experiments, fresh solutions of $344 \mu \mathrm{M}$ of EGCG (Sigma Aldrich, number 989-51-5) were prepared by dissolving EGCG in 100 mM sodium phosphate buffer $\mathrm{pH} 2.4$, supplemented with $100 \mathrm{mM} \mathrm{NaCl}$ or in $20 \%$ acetic acid, supplemented with $100 \mathrm{mM} \mathrm{NaCl}$, just before the experiment. EGCG $\mathrm{E}_{0 x}$ was prepared by dissolving $10 \mathrm{mM}$ of EGCG in $10 \mathrm{mM}$ phosphate buffer solution, $\mathrm{pH} 7.4$, and incubation for $8 \mathrm{~h}$ at $60^{\circ} \mathrm{C}$ in a thermomixer MHR 23 (Ditabis, Pforzheim, Germany). Subsequently, it was diluted to a final concentration of $344 \mu \mathrm{M}$ using PB or AC.

The $\alpha$-synuclein in the pT7-7 vector was expressed in Escherichia coli BL21 (DE3) and purified as previously described [25]. As a last step, $\alpha$-synuclein was purified by size-exclusion chromatography on an ÄKTA pure chromatography system (GE Healthcare) using a Superdex 200 Increase 10/300 GL (GE Healthcare) and $20 \mathrm{mM}$ citric acid, $\mathrm{pH} 7$, as an elution buffer. $\alpha$-synuclein concentration was determined by measuring UV-absorption at $275 \mathrm{~nm}$ (extinction coefficient of $5600 \mathrm{M}^{-1} \mathrm{~cm}^{-1}$ ). For the $\alpha$-synuclein inhibition experiments, $5 \mathrm{mM}$ solutions of EGCG (Tocris, Abingdon, UK, number 4524) were prepared by dissolving EGCG in $\mathrm{dH}_{2} \mathrm{O}$. The solutions were frozen and stored at $-20^{\circ} \mathrm{C}$, after monitoring no difference between fresh and thawed EGCG. EGCG ${ }_{0 x}$ was prepared by dissolving $10 \mathrm{mM}$ of EGCG in $20 \mathrm{mM}$ citric acid, $\mathrm{pH} \mathrm{7}$, and incubation for $6 \mathrm{~h}$ at $60{ }^{\circ} \mathrm{C}$ in a thermomixer. Subsequently, it was diluted to a final concentration of $5 \mathrm{mM}$, frozen and stored at $-20^{\circ} \mathrm{C}$.

\subsection{Measurements of Aggregation Kinetics}

Insulin: For the inhibition experiments, $344 \mu \mathrm{M}$ solutions of EGCG or $\mathrm{EGCG}_{0 x}$ were mixed with $344 \mu \mathrm{M}$ insulin solutions in a 1:1 ratio. Three replicates of each solution were then pipetted into a nonbinding surface plate (NBS; Corning, Corning, NY, USA, number 3881). The plate was sealed using sealing tape (Nunc, Roskilde, Denmark, number 232701). Kinetics of insulin aggregation was monitored at $60^{\circ} \mathrm{C}$ without (quiescent conditions) and with continuous shaking (960 rpm; agitated conditions) by measuring ThT fluorescence emission intensity (excitation-440 nm; emission-480 nm) through the bottom of the plate using a Synergy H4 Hybrid Multi-Mode (Biotek, Winooski, VT, USA) microplate reader for $15 \mathrm{~h}$ (readouts were taken every $5 \mathrm{~min}$ under quiescent conditions and every 2 min under agitated conditions). Three independent measurements were performed for each sample.

$\alpha$-synuclein: To study the effect of EGCG on the $\alpha$-synuclein fibril formation, solutions of $25 \mu \mathrm{M}$ of $\alpha$-synuclein were prepared with EGCG or EGCG Ex $_{0}$ solutions in a 1:1 ratio, $20 \mu \mathrm{M}$ ThT and $150 \mathrm{mM}$ citric acid at the wanted $\mathrm{pH}$-value ( $\mathrm{pH} 6$ or $\mathrm{pH}$ 7). Three replicates of each solution were then pipetted into a high binding surface plate Costar (Corning, number 3601) and glass beads were added into the wells. The plate was sealed using SealPlate film (Sigma-Aldrich, number Z369667). Kinetics of amyloid formation were monitored at $37^{\circ} \mathrm{C}$ under continuous shaking ( $300 \mathrm{rpm}$ ) by measuring ThT fluorescence intensity through the bottom of the plate using FLUOstar (BMG LABTECH, Ortenberg, Germany) microplate reader (readouts were taken every $5 \mathrm{~min}$ ).

The highest ThT fluorescence emission value within each curve was assumed to be $I_{\max }$. Half-times $\left(t_{50}\right)$ of the aggregation process were obtained as described by Nielsen et al. [55]. Briefly, experimental data was fitted using the following sigmoidal equation:

$$
Y=y_{i}+m_{i} t+\frac{y_{f}+m_{f} t}{1+e^{-\left(\frac{t-t_{50}}{\tau}\right)}},
$$

where $Y$ is the ThT fluorescence emission intensity, $t$ is the time, and $t_{50}$ is the time when $50 \%$ of maximum ThT fluorescence intensity is reached. The initial baseline is described by $y_{i}+m_{i} t$ and the final baseline is described by $y_{f}+m_{f} t$. 


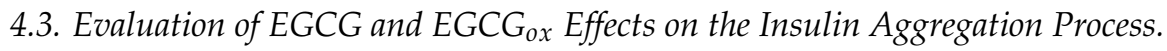

The effects of EGCG and EGCG Ex $_{x}$ on the insulin aggregation process were determined by comparing experimental values of $t_{50}$ or $I_{\max }$ of control samples with the ones determined in the presence of EGCG or EGCG $0 x$ using one-way the one-way analysis of variance (ANOVA). $p<0.01$ was accepted as statistically significant. The analysis was performed using OriginPro software.

\subsection{Atomic Force Microscopy (AFM)}

Insulin: Directly after the kinetic measurements, the samples were collected, and $20 \mu \mathrm{L}$ of each sample was deposited on freshly cleaved mica and incubated for $1 \mathrm{~min}$. Subsequently, the samples were rinsed with $1 \mathrm{~mL}$ of MilliQ water and dried under gentle airflow. Three-dimensional AFM maps were acquired using a Dimension Icon (Bruker) atomic force microscope operating in tapping mode, equipped with a silicon cantilever Tap300AI-G $\left(40 \mathrm{~N} \mathrm{~m}^{-1}\right.$, Budget Sensors) with a typical tip radius of curvature of $8 \mathrm{~nm}$. High-resolution $(1024 \times 1024$ pixels $)$ images were acquired. The scan rate was 0.5 Hz. AFM images were flattened using SPIP (Image Metrology, Hessholm, Denmark) or NanoScope Analysis (Bruker, Billerica, MA, USA) software.

$\alpha$-synuclein: AFM images were acquired directly after the aggregation kinetic measurements. In total, $10 \mu \mathrm{L}$ of each sample was deposited onto freshly cleaved mica. After drying, the samples were washed 5 times with $100 \mu \mathrm{L}$ of $\mathrm{dH}_{2} \mathrm{O}$ and dried under gentle flow of nitrogen. Three-dimensional AFM maps were obtained using a NanoScope V (Bruker) atomic force microscope equipped with a silicon cantilever ScanAsyst-Air (Bruker) with a tip radius of 2-12 nm. High-resolution $(1024 \times 1024$ pixels) images were acquired. The scan rate was $0.9 \mathrm{~Hz}$. AFM images were flattened using SPIP (Image Metrology) software.

\subsection{Fourier-Transform Infrared (FTIR) Spectroscopy}

Insulin fibrils were separated from buffer solution by centrifugation at $10,000 \times g$ for $30 \mathrm{~min}$ and subsequently resuspended in $1 \mathrm{~mL}$ of $\mathrm{D}_{2} \mathrm{O}$; the procedure was repeated three times. Finally, fibrils were resuspended in $0.3 \mathrm{~mL}$ of $\mathrm{D}_{2} \mathrm{O}$ and sonicated for $1 \mathrm{~min}$ using Sonopuls 3100 (Bandelin, Berlin, Germany) ultrasonic homogeniser equipped with MS73 tip (using 50\% of the power; total energy applied to the sample $\sim 1.12 \mathrm{~kJ}$ ). Samples were deposited between two $\mathrm{CaF}_{2}$ transmission windows separated by $0.05 \mathrm{~mm}$ teflon spacers. The FTIR spectra were recorded using a Vertex $80 \mathrm{v}$ (Bruker) IR spectrometer equipped with a mercury cadmium telluride detector, at room temperature under vacuum ( $\sim 2 \mathrm{mBar}$ ) conditions. A total of 256 interferograms of $2 \mathrm{~cm}^{-1}$ resolution were averaged for each spectrum. The spectrum of $\mathrm{D}_{2} \mathrm{O}$ was subtracted from the spectrum of each sample. All spectra were normalised to the same area of amide I/I' band $\left(1700-1595 \mathrm{~cm}^{-1}\right)$. All data processing was performed using GRAMS software.

\subsection{Microfluidic Diffusional Sizing and Concentration Measurements}

To measure the concentration of the soluble $\alpha$-synuclein, the samples were centrifuged for $60 \mathrm{~min}$ at $16,100 \times g$ at $25^{\circ} \mathrm{C}$ using a centrifuge $5415 \mathrm{R}$ (Eppendorf) directly after the kinetic measurements. The supernatant was taken, and $6 \mu \mathrm{L}$ was pipetted onto a disposable microfluidic chip and measured with the FluidityOne (Fluidic Analytics, Cambridge, UK). FluidityOne is a microfluidic diffusional sizing (MDS, [60]) device, which measures the rate of diffusion under steady state, laminar flow. The protein concentration is determined by fluorescence intensity, as the protein is mixed with ortho-phthalaldehyde (OPA) after the diffusion, a compound which reacts with primary amines, producing a fluorescent compound [61].

\subsection{Time Course of EGCG Oxidation}

The oxidation of EGCG was followed by UV-Vis spectroscopy. Solutions of EGCG were prepared as described above. In total, $10 \mathrm{mM}$ EGCG solutions were dissolved in $10 \mathrm{mM}$ sodium phosphate 
buffer $\mathrm{pH} 7.4$, corresponding to the conditions under which a stock solution of $\mathrm{EGCG}_{o x}$ for insulin experiments was produced, and in $20 \mathrm{mM}$ citric acid, $\mathrm{pH}$ 7, corresponding to the conditions under which a stock solution of $\mathrm{EGCG}_{0 x}$ for the $\alpha$-synuclein experiments was produced. The oxidation of EGCG was carried out by incubating the solutions at $60^{\circ} \mathrm{C}$ for $0-22 \mathrm{~h}$. Subsequently, the solutions were diluted and the spectra were recorded in the wavelength range between $250 \mathrm{~nm}$ and $500 \mathrm{~nm}$ in a UV-transparent plate (Corning, Corning, NY, USA, number 3679) using a Spark (Tecan, Mannedorf, Switzerland) microplate reader. To monitor the stability of EGCG under the used aggregation experiments, $172 \mu \mathrm{M}$ EGCG in $100 \mathrm{mM} \mathrm{NaCl}, 100 \mathrm{mM}$ sodium phosphate buffer, pH 2.4, $172 \mu \mathrm{M}$ EGCG in $20 \%$ acetic acid, and $100 \mathrm{mM} \mathrm{NaCl}$ were incubated at $60^{\circ} \mathrm{C}$ for $0-22 \mathrm{~h}$, corresponding to the conditions of the insulin aggregation experiments, and $125 \mu \mathrm{M}$ EGCG in $150 \mathrm{mM}$ citric acid at pH 6 and $\mathrm{pH} 7$ were incubated at $37^{\circ} \mathrm{C}$ for $0-22 \mathrm{~h}$, corresponding to the conditions of the $\alpha$-synuclein aggregation experiments.

Supplementary Materials: The following are available online at http:/ /www.mdpi.com/2218-273X/9/12/855/s1 , Figure S1: Representative curves of insulin aggregation kinetics in the absence and presence of EGCG or EGCG $0 x$ under different environmental conditions. Figure S2: EGCG oxidation followed by UV-Vis spectroscopy. Figure S3: AFM images of insulin fibrils formed in PB under quiescent conditions in the absence and presence of EGCG or EGCG Ex . Figure S4: AFM images of insulin fibrils formed in PB under agitated conditions in the absence and presence of EGCG or EGCG $0 x$. Figure S5: AFM images of insulin fibrils formed in AC under quiescent conditions

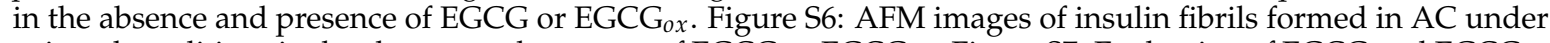
agitated conditions in the absence and presence of EGCG or EGCG $0 x$. Figure S7: Evaluation of EGCG and EGCG $0 x$ effects on $t_{50}$ and $I_{\max }$ using one-way ANOVA. Figure S8: Second derivative FTIR spectra of insulin amyloid-like aggregates formed in AC in the absence and presence of EGCG Ex $_{0}$. Figure S9: Effect of EGCG $\mathrm{Ex}_{0 x}$ on $t_{50}$ and $I_{\max }$ in AC assessed in NBS-plates and untreated-plates. Raw data of insulin and $\alpha$-synuclein aggregation kinetics; microfluidic diffusional sizing and concentration measurements; UV-Vis spectra of EGCG oxidation; FTIR spectra of insulin aggregates.

Author Contributions: Conceptualisation, T.S. A.S., R.S.-H., A.K.B., and V.S.; funding acquisition, A.K.B. and V.S.; Supervision; A.K.B. and V.S.; investigation, T.S., A.S., R.S.-H., A.P., and M.Z.; Resources, A.K.B. and V.S.; writing-original draft preparation, T.S., A.K.B., and V.S.; writing-review and editing, T.S., A.S., R.S.-H., M.Z., A.K.B., and V.S.

Funding: This research was funded by the Marie Curie Career Integration Grant 293476. A.K.B. and R.S.H. thank the Manchot Foundation for funding. A.K.B. thanks the Novo Nordisk Foundation for funding through a Novo Nordisk Foundation Professorship.

Acknowledgments: The authors acknowledge G. Niaura from the Center of Physical Sciences and Technology for the access to FTIR.

Conflicts of Interest: The authors declare no conflict of interest.

\section{References}

1. Chiti, F.; Dobson, C.M. Protein misfolding, amyloid formation, and human disease: A summary of progress over the last decade. Annu. Rev. Biochem. 2017, 86, 27-68, doi:10.1146/annurev-biochem-061516-045115. [CrossRef] [PubMed]

2. Knowles, T.P.J.; Vendruscolo, M.; Dobson, C.M. The amyloid state and its association with protein misfolding diseases. Nat. Rev. Mol. Cell Biol. 2014, 15, 384-396, doi:10.1038/nrm3810. [CrossRef] [PubMed]

3. Selkoe, D.J.; Hardy, J. The amyloid hypothesis of Alzheimer's disease at 25 years. EMBO Mol. Med. 2016, 8, 595-608, doi:10.15252/emmm.201606210. [CrossRef] [PubMed]

4. Wisniewski, T.; Goñi, F. Immunotherapeutic approaches for Alzheimer's disease. Neuron 2015, 85, 1162-1176, doi:10.1016/j.neuron.2014.12.064. [CrossRef]

5. Fitzpatrick, A.W.P.; Debelouchina, G.T.; Bayro, M.J.; Clare, D.K.; Caporini, M.A.; Bajaj, V.S.; Jaroniec, C.P.; Wang, L.; Ladizhansky, V.; Muller, S.A.; et al. Atomic structure and hierarchical assembly of a cross-beta amyloid fibril. Proc. Natl. Acad. Sci. USA 2013, 110, 5468-5473, doi:10.1073/pnas.1219476110. [CrossRef]

6. Porat, Y.; Abramowitz, A.; Gazit, E. Inhibition of amyloid fibril formation by polyphenols: Structural similarity and aromatic interactions as a common inhibition mechanism. Chem. Biol. Drug Des. 2006, 67, 27-37, doi:10.1111/j.1747-0285.2005.00318.x. [CrossRef]

7. Doig, A.J.; Derreumaux, P. Inhibition of protein aggregation and amyloid formation by small molecules. Current Opin. Struct. Biol. 2015, 30, 50-56, doi:10.1016/j.sbi.2014.12.004. [CrossRef] 
8. Mangialasche, F.; Solomon, A.; Winblad, B.; Mecocci, P.; Kivipelto, M. Alzheimer's disease: Clinical trials and drug development. Lancet Neurol. 2010, 9, 702-716, doi:10.1016/S1474-4422(10)70119-8. [CrossRef]

9. Castellani, R.J.; Plascencia-Villa, G.; Perry, G. The amyloid cascade and Alzheimer's disease therapeutics: Theory versus observation. Lab. Investig. 2019, 99, 958-970, doi:10.1038/s41374-019-0231-z. [CrossRef]

10. Cheng, B.; Gong, H.; Xiao, H.; Petersen, R.B.; Zheng, L.; Huang, K. Inhibiting toxic aggregation of amyloidogenic proteins: A therapeutic strategy for protein misfolding diseases. Biochim. Biophys. Acta Gen. Subj. 2013, 1830, 4860-4871, doi:10.1016/j.bbagen.2013.06.029. [CrossRef]

11. Lao, K.; Ji, N.; Zhang, X.; Qiao, W.; Tang, Z.; Gou, X. Drug development for Alzheimer's disease: Review. J. Drug Target. 2019, 27, 164-173, doi:10.1080/1061186X.2018.1474361. [CrossRef]

12. Stefani, M.; Rigacci, S. Protein folding and aggregation into amyloid: The interference by natural phenolic compounds. Int. J. Mol. Sci. 2013, 14, 12411-12457, doi:10.3390/ijms140612411. [CrossRef]

13. Molino, S.; Dossena, M.; Buonocore, D.; Ferrari, F.; Venturini, L.; Ricevuti, G.; Verri, M. Polyphenols in dementia: From molecular basis to clinical trials. Life Sci. 2016, 161, 69-77, doi:10.1016/j.lfs.2016.07.021. [CrossRef]

14. Goyal, D.; Shuaib, S.; Mann, S.; Goyal, B. Rationally designed peptides and peptidomimetics as inhibitors of amyloid- $\beta$ (A $\beta)$ aggregation: Potential therapeutics of Alzheimer's disease. ACS Comb. Sci. 2017, 19, 55-80. doi:10.1021/acscombsci.6b00116. [CrossRef] [PubMed]

15. Agerschou, E.D.; Flagmeier, P.; Saridaki, T.; Galvagnion, C.; Komnig, D.; Nagpal, A.; Gasterich, N.; Heid, L.; Prasad, V.; Shaykhalishahi, H.; et al. An engineered monomer binding-protein for $\alpha$-synuclein efficiently inhibits the proliferation of amyloid fibrils. eLife 2019, 8, e46112. [CrossRef] [PubMed]

16. Mehta, D.; Jackson, R.; Paul, G.; Shi, J.; Sabbagh, M. Why do trials for Alzheimer's disease drugs keep failing? A discontinued drug perspective for 2010-2015. Expert Opin. Investig. Drugs 2017, 26, 735-739, doi:10.1080/13543784.2017.1323868. [CrossRef] [PubMed]

17. Mathur, S.; Dewitte, S.; Robledo, I.; Isaacs, T.; Stamford, J. Rising to the challenges of clinical trial improvement in Parkinson's disease. J. Parkinson's Dis. 2015, 5, 263-268, doi:10.3233/JPD-150541. [CrossRef] [PubMed]

18. Athauda, D.; Foltynie, T. Challenges in detecting disease modification in Parkinson's disease clinical trials. Parkinsonism Relat. Disord. 2016, 32, 1-11, doi:10.1016/j.parkreldis.2016.07.019. [CrossRef]

19. Al-Ansari, A.; Robertson, N.P. Creutzfeldt-Jacob disease: New directions in diagnosis and therapeutics. J. Neurol. 2017, 264, 1029-1031, doi:10.1007/s00415-017-8473-4. [CrossRef]

20. Yaari, R.; Hake, A. Alzheimer's disease clinical trials: Past failures and future opportunities. Clin. Investig. 2015, 5, 297-309, doi:10.4155/cli.14.127. [CrossRef]

21. Cummings, J.L.; Morstorf, T.; Zhong, K. Alzheimer's disease drug-development pipeline: Few candidates, frequent failures. Alzheimer's Res. Ther. 2014, 6, 37, doi:10.1186/alzrt269. [CrossRef] [PubMed]

22. Sneideris, T.; Darguzis, D.; Botyriute, A.; Grigaliunas, M.; Winter, R.; Smirnovas, V. pH-driven polymorphism of insulin amyloid-like fibrils. PLOS ONE 2015, 10, e0136602, doi:10.1371/journal.pone.0136602. [CrossRef] [PubMed]

23. Ziaunys, M.; Sneideris, T.; Smirnovas, V. Self-inhibition of insulin amyloid-like aggregation. Phys. Chem. Chem. Phys. 2018, 20, 27638-27645, doi:10.1039/C8CP04838J. [CrossRef] [PubMed]

24. Sneideris, T.; Milto, K.; Smirnovas, V. Polymorphism of amyloid-like fibrils can be defined by the concentration of seeds. Peer] 2015, 3, e1207, doi:10.7717/peerj.1207. [CrossRef] [PubMed]

25. Buell, A.K.; Galvagnion, C.; Gaspar, R.; Sparr, E.; Vendruscolo, M.; Knowles, T.P.J.; Linse, S.; Dobson, C.M. Solution conditions determine the relative importance of nucleation and growth processes in $\alpha$-synuclein aggregation. Proc. Natl. Acad. Sci. USA 2014, 111, 7671-7676, doi:10.1073/pnas.1315346111. [CrossRef] [PubMed]

26. Guo, J.L.; Lee, V.M.Y. Cell-to-cell transmission of pathogenic proteins in neurodegenerative diseases. Nat. Med. 2014, 20, 130-138, doi:10.1038/nm.3457. [CrossRef] [PubMed]

27. Adamcik, J.; Mezzenga, R. Amyloid polymorphism in the protein folding and aggregation energy landscape. Angew. Chem. Int. Ed. 2018, 57, 8370-8382, doi:10.1002/anie.201713416. [CrossRef]

28. Wei, Y.; Chen, P.; Ling, T.; Wang, Y.; Dong, R.; Zhang, C.; Zhang, L.; Han, M.; Wang, D.; Wan, X.; et al. Certain (-)-epigallocatechin-3-gallate (EGCG) auto-oxidation products (EAOPs) retain the cytotoxic activities of EGCG. Food Chem. 2016, 204, 218-226, doi:10.1016/j.foodchem.2016.02.134. [CrossRef] 
29. An, T.T.; Feng, S.; Zeng, C.M. Oxidized epigallocatechin gallate inhibited lysozyme fibrillation more strongly than the native form. Redox Biol. 2017, 11, 315-321, doi:10.1016/j.redox.2016.12.016. [CrossRef]

30. Palhano, F.L.; Lee, J.; Grimster, N.P.; Kelly, J.W. Toward the molecular mechanism(s) by which EGCG treatment remodels mature amyloid fibrils. J. Am. Chem. Soc. 2013, 135, 7503-7510, doi:10.1021/ja3115696. [CrossRef]

31. Attar, A.; Rahimi, F.; Bitan, G. Modulators of amyloid protein aggregation and toxicity: EGCG and CLR01. Transl. Neurosci. 2013, 4, 385-409, doi:10.2478/s13380-013-0137-y. [CrossRef]

32. Liu, Y.; Liu, Y.; Wang, S.; Dong, S.; Chang, P.; Jiang, Z. Structural characteristics of (-)-epigallocatechin-3-gallate inhibiting amyloid A $\beta 42$ aggregation and remodeling amyloid fibers. RSC Adv. 2015, 5, 62402-62413, doi:10.1039/c5ra09608a. [CrossRef]

33. Bieschke, J.; Russ, J.; Friedrich, R.P.; Ehrnhoefer, D.E.; Wobst, H.; Neugebauer, K.; Wanker, E.E. EGCG remodels mature $\alpha$-synuclein and amyloid- $\beta$ fibrils and reduces cellular toxicity. Proc. Natl. Acad. Sci. USA 2010, 107, 7710-7715, doi:10.1073/pnas.0910723107. [CrossRef] [PubMed]

34. Zhao, J.; Liang, Q.; Sun, Q.; Chen, C.; Xu, L.; Ding, Y.; Zhou, P. (-)-Epigallocatechin-3-gallate (EGCG) inhibits fibrillation, disaggregates amyloid fibrils of $\alpha$-synuclein, and protects PC12 cells against $\alpha$-synuclein-induced toxicity. RSC Adv. 2017, 7, 32508-32517, doi:10.1039/c7ra03752j. [CrossRef]

35. Qing, H.; McGeer, P.L.; Zhang, Y.; Yang, Q.; Dai, R.; Zhang, R.; Guo, J.; Wong, W.; Xu, Y.; Quan, Z. Epigallocatechin gallate (EGCG) inhibits alpha-synuclein aggregation: A potential agent for Parkinson's disease. Neurochem. Res. 2016, 41, 2788-2796, doi:10.1007/s11064-016-1995-9. [CrossRef]

36. Roy, S.; Bhat, R. Suppression, disaggregation, and modulation of $\gamma$-Synuclein fibrillation pathway by green tea polyphenol EGCG. Protein Sci. 2019, 28, 382-402. doi:10.1002/pro.3549. [CrossRef]

37. Lee, Y.H.; Lin, Y.; Cox, S.J.; Kinoshita, M.; Sahoo, B.R.; Ivanova, M.; Ramamoorthy, A. Zinc boosts EGCG's hIAPP amyloid Inhibition both in solution and membrane. Biochim. Biophys. Acta (BBA) Proteins Proteom. 2019, 1867, 529-536. [CrossRef]

38. Xu, Z.X.; Ma, G.L.; Zhang, Q.; Chen, C.H.; He, Y.M.; Xu, L.H.; Zhou, G.R.; Li, Z.H.; Yang, H.J.; Zhou, P. Inhibitory mechanism of epigallocatechin gallate on fibrillation and aggregation of amidated human islet amyloid polypeptide. ChemPhysChem 2017, 18, 1611-1619. doi:10.1002/cphc.201700057. [CrossRef]

39. Ehrnhoefer, D.E.; Duennwald, M.; Markovic, P.; Wacker, J.L.; Engemann, S.; Roark, M.; Legleiter, J.; Marsh, J.L.; Thompson, L.M.; Lindquist, S.; et al. Green tea (-)-epigallocatechin-gallate modulates early events in huntingtin misfolding and reduces toxicity in Huntington's disease models. Hum. Mol. Genet. 2006, 15, 2743-2751, doi:10.1093/hmg/ddl210. [CrossRef]

40. Wobst, H.J.; Sharma, A.; Diamond, M.I.; Wanker, E.E.; Bieschke, J. The green tea polyphenol (-)-epigallocatechin gallate prevents the aggregation of tau protein into toxic oligomers at substoichiometric ratios. FEBS Lett. 2015, 589, 77-83, doi:10.1016/j.febslet.2014.11.026. [CrossRef]

41. Srinivasan, E.; Rajasekaran, R. Probing the inhibitory activity of epigallocatechin-gallate on toxic aggregates of mutant (L84F) SOD1 protein through geometry based sampling and steered molecular dynamics. J. Mol. Graph. Model. 2017, 74, 288-295, doi:10.1016/j.jmgm.2017.04.019. [CrossRef] [PubMed]

42. Roberts, B.E.; Duennwald, M.L.; Wang, H.; Chung, C.; Lopreiato, N.P.; Sweeny, E.A.; Knight, M.N.; Shorter, J. A synergistic small-molecule combination directly eradicates diverse prion strain structures. Nat. Chem. Biol. 2009, 5, 936-946, doi:10.1038/nchembio.246. [CrossRef] [PubMed]

43. Townsend, D.; Hughes, E.; Akien, G.; Stewart, K.L.; Radford, S.E.; Rochester, D.; Middleton, D.A. Epigallocatechin-3-gallate remodels apolipoprotein A-I amyloid fibrils into soluble oligomers in the presence of heparin. J. Biol. Chem. 2018, 293, 12877-12893, doi:10.1074/jbc.RA118.002038. [CrossRef] [PubMed]

44. Andrich, K.; Bieschke, J., The effect of (-)-epigallo-catechin-(3)-gallate on amyloidogenic proteins suggests a common mechanism. In Natural Compounds as Therapeutic Agents for Amyloidogenic Diseases; Vassallo, N., Ed.; Springer International Publishing: Cham, Switzerland, 2015; pp. 139-161, doi:10.1007/978-3-319-18365-7_7. [CrossRef]

45. Zhu, Q.Y.; Zhang, A.; Tsang, D.; Huang, Y.; Chen, Z.Y. Stability of green tea catechins. J. Agric. Food Chem. 1997, 45, 4624-4628, doi:10.1021/jf9706080. [CrossRef]

46. Hatano, T.; Ohyabu, T.; Yoshida, T. The structural variation in the incubation products of (-)-epigallocatechin gallate in neutral solution suggests its breakdown pathways. Heterocycles 2005, 65, doi:10.3987/COM-04-10259. [CrossRef] 
47. Sang, S.; Lee, M.J.; Hou, Z.; Ho, C.T.; Yang, C.S. Stability of tea polyphenol (-)-epigallocatechin-3-gallate and formation of dimers and epimers under common experimental conditions. J. Agric. Food Chem. 2005, 53, 9478-9484. doi:10.1021/jf0519055. [CrossRef] [PubMed]

48. Zeng, L.; Ma, M.; Li, C.; Luo, L. Stability of tea polyphenols solution with different $\mathrm{pH}$ at different temperatures. Int. J. Food Prop. 2017, 20, 1-18, doi:10.1080/10942912.2014.983605. [CrossRef]

49. Hirohata, M.; Hasegawa, K.; Tsutsumi-Yasuhara, S.; Ohhashi, Y.; Ookoshi, T.; Ono, K.; Yamada, M.; Naiki, H. The anti-amyloidogenic effect is exerted against Alzheimer's $\beta$-amyloid fibrils in vitro by preferential and reversible binding of flavonoids to the amyloid fibril structure. Biochemistry 2007, 46, 1888-1899, doi:10.1021/bi061540x. [CrossRef]

50. Haas, J.; Vohringer-Martinez, E.; Bogehold, A.; Matthes, D.; Hensen, U.; Pelah, A.; Abel, B.; Grubmuller, H. Primary steps of $\mathrm{pH}$-dependent insulin aggregation kinetics are governed by conformational flexibility. ChemBioChem 2009, 10, 1816-1822, doi:10.1002/cbic.200900266. [CrossRef]

51. Dische, F.E.; Wernstedt, C.; Westermark, G.T.; Westermark, P.; Pepys, M.B.; Rennie, J.A.; Gilbey, S.G.; Watkins, P.J. Insulin as an amyloid-fibril protein at sites of repeated insulin injections in a diabetic patient. Diabetologia 1988, 31, 158-161, doi:10.1007/BF00276849. [CrossRef]

52. Dzwolak, W.; Grudzielanek, S.; Smirnovas, V.; Ravindra, R.; Nicolini, C.; Jansen, R.; Loksztejn, A.; Porowski, S.; Winter, R. Ethanol-perturbed amyloidogenic self-assembly of insulin: Looking for origins of amyloid strains. Biochemistry 2005, 44, 8948-8958, doi:10.1021/bi050281t. [CrossRef] [PubMed]

53. Dzwolak, W.; Smirnovas, V.; Jansen, R.; Winter, R. Insulin forms amyloid in a strain-dependent manner: An FT-IR spectroscopic study. Protein Sci. Publ. Protein Soc. 2004, 13, 1927-1932, doi:10.1110/ps.03607204. [CrossRef] [PubMed]

54. Dzwolak, W.; Jansen, R.; Smirnovas, V.; Loksztejn, A.; Porowski, S.; Winter, R. Template-controlled conformational patterns of insulin fibrillar self-assembly reflect history of solvation of the amyloid nuclei. Phys. Chem. Chem. Phys. PCCP 2005, 7, 1349-1351, doi:10.1039/B502255J. [CrossRef] [PubMed]

55. Nielsen, L.; Khurana, R.; Coats, A.; Frokjaer, S.; Brange, J.; Vyas, S.; Uversky, V.N.; Fink, A.L. Effect of environmental factors on the kinetics of insulin fibril formation: Elucidation of the molecular mechanism. Biochemistry 2001, 40, 6036-6046. [CrossRef]

56. Nielsen, L.; Frokjaer, S.; Carpenter, J.F.; Brange, J. Studies of the structure of insulin fibrils by Fourier transform infrared (FTIR) spectroscopy and electron microscopy. J. Pharm. Sci. 2001, 90, 29-37, doi:10.1002/1520-6017(200101)90:1<29::AID-JPS4>3.0.CO;2-4. [CrossRef]

57. Spillantini, M.G.; Schmidt, M.L.; Lee, V.M.; Trojanowski, J.Q.; Jakes, R.; Goedert, M. Alpha-synuclein in Lewy bodies. Nature 1997, 388, 839-840, doi:10.1038/42166. [CrossRef]

58. Surmacz-Chwedoruk, W.; Babenko, V.; Dzwolak, W. Master and slave relationship between two types of self-propagating insulin amyloid fibrils. J. Phy. Chem. B 2014, 118, 13582-13589. [CrossRef]

59. Vácha, R.; Linse, S.; Lund, M. Surface effects on aggregation kinetics of amyloidogenic peptides. J. Am. Chem. Soc. 2014, 136, 11776-11782, doi:10.1021/ja505502e. [CrossRef]

60. Arosio, P.; Müller, T.; Rajah, L.; Yates, E.V.; Aprile, F.A.; Zhang, Y.; Cohen, S.I.; White, D.A.; Herling, T.W.; De Genst, E.J.; et al. Microfluidic diffusion analysis of the sizes and interactions of proteins under native solution conditions. ACS Nano 2015, 10, 333-341, doi:10.1021/acsnano.5b04713. [CrossRef]

61. Yates, E.V.; Müller, T.; Rajah, L.; De Genst, E.J.; Arosio, P.; Linse, S.; Vendruscolo, M.; Dobson, C.M.; Knowles, T.P.J. Latent analysis of unmodified biomolecules and their complexes in solution with attomole detection sensitivity. Nat. Chem. 2015, 7, 802-809, doi:10.1038/nchem.2344. [CrossRef]

62. Gang, H.; Galvagnion, C.; Meisl, G.; Müller, T.; Pfammatter, M.; Buell, A.K.; Levin, A.; Dobson, C.M.; $\mathrm{Mu}$, B.; Knowles, T.P.J. Microfluidic Diffusion Platform for Characterizing the Sizes of Lipid Vesicles and the Thermodynamics of Protein-Lipid Interactions. Anal. Chem. 2018, 90, 3284-3290, doi:10.1021/acs.analchem.7b04820. [CrossRef]

63. Arosio, P.; Vendruscolo, M.; Dobson, C.M.; Knowles, T.P.J. Chemical kinetics for drug discovery to combat protein aggregation diseases. Trends Pharmacol. Sci. 2014, 35, 127-135, doi:10.1016/j.tips.2013.12.005. [CrossRef]

64. Arosio, P.; Michaels, T.C.T.; Linse, S.; Månsson, C.; Emanuelsson, C.; Presto, J.; Johansson, J.; Vendruscolo, M.; Dobson, C.M.; Knowles, T.P.J. Kinetic analysis reveals the diversity of microscopic mechanisms through which molecular chaperones suppress amyloid formation. Nat. Commun. 2016, 7, 10948, doi:10.1038/ncomms10948. [CrossRef] 
65. Joshi, P.; Chia, S.; Habchi, J.; Knowles, T.P.; Dobson, C.M.; Vendruscolo, M. A fragment-based method of creating small-molecule libraries to target the aggregation of intrinsically disordered proteins. ACS Comb. Sci. 2016, 18, 144-153, doi:10.1021/acscombsci.5b00129. [CrossRef]

66. Andrich, K.; Hegenbart, U.; Kimmich, C.; Kedia, N.; Bergen, H.R.; Schönland, S.; Wanker, E.; Bieschke, J. Aggregation of full-length immunoglobulin light chains from systemic light chain amyloidosis (AL) patients is remodeled by epigallocatechin-3-gallate. J. Biol. Chem. 2017, 292, 2328-2344, doi:10.1074/jbc.M116.750323. [CrossRef]

67. Sneideris, T.; Baranauskiene, L.; Cannon, J.G.; Rutkiene, R.; Meskys, R.; Smirnovas, V. Looking for a generic inhibitor of amyloid-like fibril formation among flavone derivatives. PeerJ 2015, 3, e1271, doi:10.7717/peerj.1271. [CrossRef]

68. Malisauskas, R.; Botyriute, A.; Cannon, J.G.; Smirnovas, V. Flavone Derivatives as Inhibitors of Insulin Amyloid-Like Fibril Formation. PLoS ONE 2015, 10, 1-14, doi:10.1371/journal.pone.0121231. [CrossRef]

69. Aarabi, M.H. The role of two natural flavonoids on human amylin aggregation. Afr. J. Pharm. Pharmacol. 2012, 6, 2374-2379, doi:10.5897/ajpp12.616. [CrossRef]

70. Chaudhury, S.; Dutta, A.; Bag, S.; Biswas, P.; Das, A.K.; Dasgupta, S. Probing the inhibitory potency of epigallocatechin gallate against human $\gamma \mathrm{B}$-crystallin aggregation: Spectroscopic, microscopic and simulation studies. Spectrochim. Acta Part A Mol. Biomol. Spectrosc. 2018, 192, 318-327. [CrossRef]

71. Jayamani, J.; Shanmugam, G. Gallic acid, one of the components in many plant tissues, is a potential inhibitor for insulin amyloid fibril formation. Eur. J. Med. Chem. 2014, 85, 352-358, doi:10.1016/j.ejmech.2014.07.111. [CrossRef]

72. Biancalana, M.; Koide, S. Molecular mechanism of Thioflavin-T binding to amyloid fibrils. Biochim. Biophys. Acta (BBA) Proteins Proteom. 2010, 1804, 1405-1412, doi:10.1016/j.bbapap.2010.04.001. [CrossRef] [PubMed]

73. Sulatskaya, A.I.; Kuznetsova, I.M.; Belousov, M.V.; Bondarev, S.A.; Zhouravleva, G.A.; Turoverov, K.K. Stoichiometry and affinity of thioflavin T binding to Sup35p amyloid fibrils. PLoS ONE 2016, 11, 1-14, doi:10.1371/journal.pone.0156314. [CrossRef] [PubMed]

74. Ziaunys, M.; Smirnovas, V. Additional thioflavin-T binding mode in insulin fibril inner core region. J. Phys. Chem. B 2019, doi:10.1021/acs.jpcb.9b08652. [CrossRef] [PubMed]

75. Buell, A.K.; Dobson, C.M.; Knowles, T.P.J.; Welland, M.E. Interactions between Amyloidophilic Dyes and Their Relevance to Studies of Amyloid Inhibitors. Biophys. J. 2010, 99, 3492-3497, doi:10.1016/j.bpj.2010.08.074. [CrossRef] [PubMed]

76. Campioni, S.; Carret, G.; Jordens, S.; Nicoud, L.; Mezzenga, R.; Riek, R. The presence of an air-water interface affects formation and elongation of $\alpha$-synuclein fibrils. J. Am. Chem. Soc. 2014, 136, 2866-2875, doi:10.1021/ja412105t. [CrossRef] [PubMed]

77. Linse, S. Mechanism of amyloid protein aggregation and the role of inhibitors. Pure Appl. Chem. 2019, 91, 211-229, doi:10.1515/pac-2018-1017. [CrossRef]

78. Murray, A.N.; Palhano, F.L.; Bieschke, J.; Kelly, J.W. Surface adsorption considerations when working with amyloid fibrils in multiwell plates and Eppendorf tubes. Protein Sci. 2013, 22, 1531-1541, doi:10.1002/pro.2339. [CrossRef]

79. Risor, M.W.; Juhl, D.W.; Bjerring, M.; Mathiesen, J.; Enghild, J.J.; Nielsen, N.C.; Otzen, D.E. Critical influence of cosolutes and surfaces on the assembly of serpin-derived amyloid fibrils. Biophys. J. 2017, 113, 580-596. [CrossRef]

80. Zhu, M.; Han, S.; Fink, A. Oxidized quercetin inhibits $\alpha$-synuclein fibrillization. Biochim. Biophys. Acta 2013, 1830, 2872-2881. [CrossRef]

81. Daniels, M.J.; Nourse, J.B.; Kim, H.; Sainati, V.; Schiavina, M.; Murrali, M.G.; Pan, B.; Ferrie, J.J.; Haney, C.M.; Moons, R.; et al. Cyclized NDGA modifies dynamic $\alpha$-synuclein monomers preventing aggregation and toxicity. Sci. Rep. 2019, 9, 2937, doi:10.1038/s41598-019-39480-z. [CrossRef] 
82. Mak, S.K.; McCormack, A.L.; Manning-Bog, A.B.; Cuervo, A.M.; Monte, D.A.D. Lysosomal degradation of alpha-synuclein in vivo. J. Biol. Chem. 2010, 285, 13621-13629, doi:10.1074/jbc.M109.074617. [CrossRef] [PubMed]

83. Bourdenx, M.; Bezard, E.; Dehay, B. Lysosomes and $\alpha$-synuclein form a dangerous duet leading to neuronal cell death. Front. Neuroanat. 2014, 8, 83, doi:10.3389/fnana.2014.00083. [CrossRef] [PubMed]

(c) 2019 by the authors. Licensee MDPI, Basel, Switzerland. This article is an open access article distributed under the terms and conditions of the Creative Commons Attribution (CC BY) license (http:/ / creativecommons.org/licenses/by/4.0/). 